\title{
Cu-Catalyzed Vapor-Liquid-Solid Growth of SiGe Microwire Arrays with Chlorosilane and Chlorogermane Precursors
}

\author{
Christopher T. Chen, ${ }^{\dagger}$ Hal S. Emmer, ${ }^{\dagger}$ Shaul Aloni, ${ }^{\ddagger}$ Daniel B. Turner-Evans, ${ }^{\dagger, \#}$ and Harry A. Atwater* ${ }^{\dagger}$ \\ ${ }^{\dagger}$ Thomas J. Watson Laboratory of Applied Physics, California Institute of Technology, Pasadena, California 91125, United States \\ ${ }^{\ddagger}$ Molecular Foundry, Lawrence Berkeley National Laboratory, Berkeley, California 94720, United States
}

Supporting Information

ABSTRACT: Selected area Cu-catalyzed vapor-liquid-solid growth of SiGe microwires is achieved using chlorosilane and chlorogermane precursors. The composition can be tuned up to $12 \%$ Ge with a simultaneous decrease in the growth rate from 7 to $1 \mu \mathrm{m} \mathrm{min}{ }^{-1}$. Significant changes to the morphology were observed, including tapering and faceting on the sidewalls and along the lengths of the wires. Characterization of axial and radial cross sections with transmission electron microscopy revealed no evidence of defects at facet corners and edges, and the tapering is shown to be due to in situ removal of catalyst material during growth. X-ray diffraction and transmission electron microscopy reveal a Ge-rich crystal at the tip of the wires, strongly suggesting that the Ge incorporation is limited by the crystallization rate.

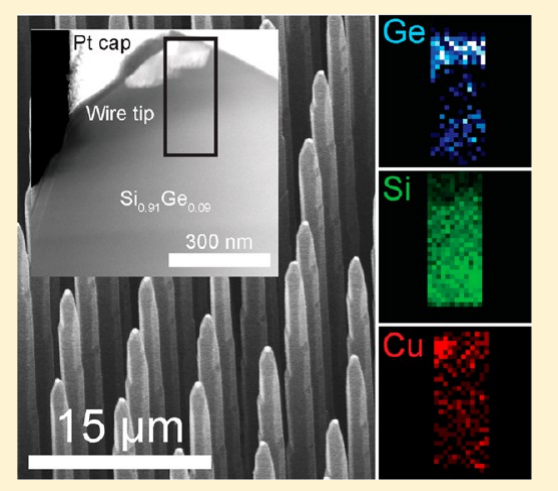

\section{INTRODUCTION}

Since the seminal work of Wagner and Ellis, ${ }^{1}$ vapor-liquidsolid growth has been applied to the growth of a variety of semiconductor nano- and microwires. The unique properties of these high aspect ratio structures make them promising candidates for use in many types of devices, including photovoltaic, ${ }^{2}$ photoelectrochemical, ${ }^{3,4}$ optoelectronic, ${ }^{5}$ and thermoelectric. ${ }^{6,7} \mathrm{SiGe}$ alloy wires are particularly interesting as a growth substrate for lattice matched $\mathrm{III}-\mathrm{V}^{8}$ or strained silicon shells. Nanoscale SiGe wires, in particular, have been of interest for the ability to independently tune composition and size. $^{8}$ A majority of the existing work in the literature has been focused on vapor-liquid-solid growth of $\mathrm{Si}_{1-x} \mathrm{Ge}_{x}$ nanowires using silane and germane precursors with $\mathrm{Au}$ catalysts at low pressures, ${ }^{7,9-14}$ and full compositional control has been demonstrated. ${ }^{9,15}$ Significant progress has been made in the development of axial ${ }^{16}$ and radial ${ }^{17}$ heterostructures with sharp interfaces. In contrast to much of the existing work, atmospheric pressure $\mathrm{Cu}$-catalyzed vapor-liquid-solid growth with tetrachlorosilane has been shown to generate vertically aligned, monodisperse arrays of microwires with micron-scale diameters and heights. ${ }^{18,19}$ Chlorinated precursors offer several advantages for use in chemical vapor deposition growth compared to their hydride counterparts, including improving array fidelity by etching noncatalyzed growth on the sidewalls and around the wire bases, ${ }^{20}$ and very high growth rates ${ }^{21,22}$ compared to silane. ${ }^{23}$ Finally, chloride based precursors are safer than hydrides, due to their lower toxicity and flammability. ${ }^{24}$

We demonstrate atmospheric pressure, $\mathrm{Cu}$-catalyzed, vaporliquid-solid grown $\mathrm{Si}_{1-x} \mathrm{Ge}_{x}$ microwire arrays using chlorosilane and chlorogermane precursors. Similar to Si wire arrays, the $\mathrm{Si}_{1-x} \mathrm{Ge}_{x}$ microwire arrays can be grown over $\sim 1 \mathrm{~cm}^{2}$ areas with high aspect ratio wires growing vertically from a patterned oxide on $\mathrm{Si}$ (111) substrates. The work presented here explores a $\mathrm{Si}_{1-x} \mathrm{Ge}_{x}$ wire size, growth temperature, and reactor pressure regime different from those explored previously. To the best of our knowledge, this is also the first report of $\mathrm{Cu}$-catalyzed vapor-liquid-solid growth of these alloys with chloride precursors. An increase in the Ge precursor flow led to an expected increase in Ge content and an unexpected reduction of the growth rate. Ge incorporation was limited to $\leq 12 \%$, unlike the full compositional tunability demonstrated for random Au-catalyzed growth of $\mathrm{SiGe}$ nanowires with silane and germane precursors. ${ }^{9,15}$ Consistent with the work of Soman et al. on thin film growth, ${ }^{25}$ contamination from adventitious Ge species on reactor surfaces makes reproducibility more challenging than for pure silicon growth, and in our case contamination results in growth of disordered nano- and microwire forests instead of vertical microwires. Improved reproducibility was achieved by alternating $\mathrm{SiGe}$ wire growths with pure Si growth, in effect keeping the reactor in a steady state. The SiGe wire morphology, composition, and crystallinity were carefully monitored from run to run with scanning electron microscopy, energy-dispersive $\mathrm{X}$-ray spectroscopy, and $\mathrm{X}$-ray diffraction. Cross sections of single wires examined with transmission electron microscopy reveal a Ge-rich layer at the tip of the wire.

Received: February 28, 2015

Revised: June 23, 2015 
$[\mathrm{Ge}][\mathrm{IV}]=2.9 \%$

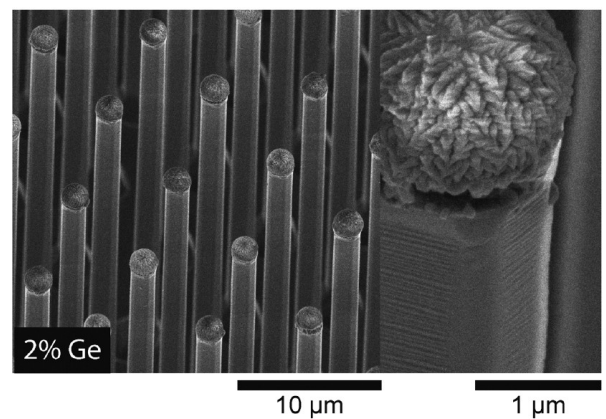

$[\mathrm{Ge}] /[\mathrm{IV}]=10.1 \%$

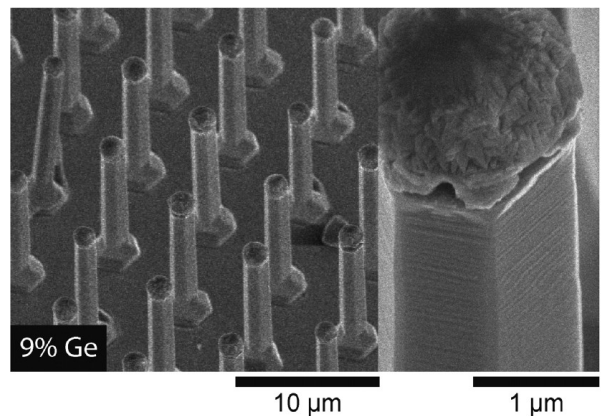

$[\mathrm{Ge}][\mathrm{IV}]=5.1 \%$

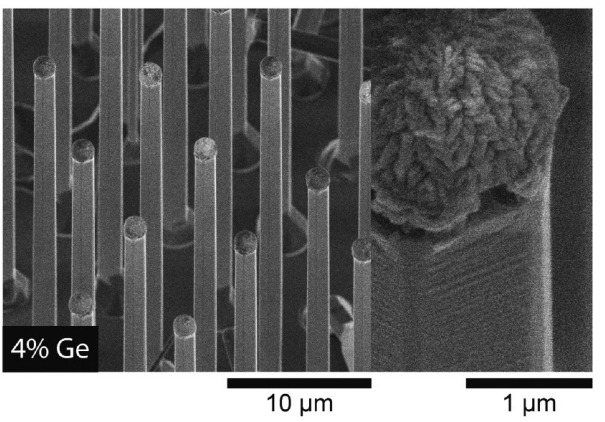

$[\mathrm{Ge}] /[\mathrm{IV}]=18.6 \%$

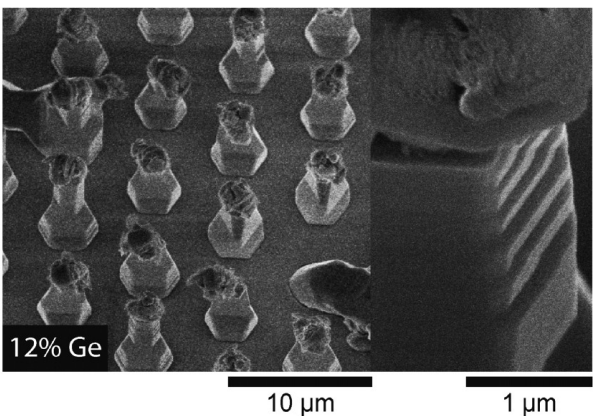

Figure 1. Scanning electron micrographs of $\mathrm{Si}_{1-x} \mathrm{Ge}_{x}$ wire arrays grown with increasing $\mathrm{GeCl}_{4}$ flow rates and constant $\mathrm{SiCl}_{4}$ flow for 10 min. The growth rate drops from $7 \mu \mathrm{m} \mathrm{min}^{-1}$ at the lowest to $1 \mu \mathrm{m} \mathrm{min}^{-1}$ at the highest [Ge]/[IV] ratio. Large sidewall facets are introduced gradually as the $[\mathrm{Ge}] /[\mathrm{IV}]$ ratio increases until they dominate the sidewall morphology at $[\mathrm{Ge}] /[\mathrm{IV}]=18.6 \%$.

\section{EXPERIMENTAL SECTION}

Wire Array Growth. High purity (6 N, Alfa Aesar) Cu-catalyst decorated $\mathrm{Si}$ (111) substrates were prepared with standard photolithographic liftoff processes as described elsewhere. ${ }^{21}$ Substrates were cleaved to $1 \mathrm{~cm}^{2}$ pieces and loaded onto a boat in our atmospheric pressure hot wall chemical vapor deposition reactor at $750{ }^{\circ} \mathrm{C}$. Typical growth parameters include $1 \mathrm{slm}$ of $\mathrm{H}_{2}$ carrier gas, bubbled $\mathrm{H}_{2}$ carrier gas through a nominally $32{ }^{\circ} \mathrm{C} \mathrm{GeCl}_{4}$ cylinder, and collection of the overpressure from a $\mathrm{SiCl}_{4}$ cylinder heated to $85{ }^{\circ} \mathrm{C}$ at a growth temperature of $1000{ }^{\circ} \mathrm{C}$. We use molar flow rates of $0-98 \mu \mathrm{mol} \mathrm{min}^{-1}$

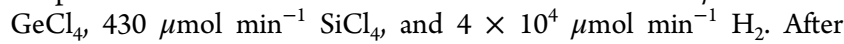
growth, samples were cooled slowly to $750{ }^{\circ} \mathrm{C}$ inside the tube, then removed.

Scanning Electron Microscopy. Micrographs were collected using either a Hitachi S-4100 FE-SEM, an FEI Nova 600, or an FEI Nova 200 dual beam scanning electron microscope and focused ion beam by first aligning to the growth axis and then tilting to $30^{\circ}$ offnormal incidence. The FEI Nova 200 was also used for energy dispersive spectroscopy of as-grown wire arrays for compositional verification using an Ametek EDAX Genesis 7000 and a Sapphire detector.

X-ray Diffractometry. High resolution X-ray diffractometry was performed on a Panalytical X'Pert Pro, with a hybrid X-ray mirror/2bounce monochromator and a $3 \times 220 \mathrm{Ge}$ analyzer with a sealed $\mathrm{Xe}$ proportional detector. Reciprocal space maps were collected after first aligning to the (111) or (153) peak of the Si substrate. Relaxation was calculated using the methodology described in Zhylik et al. ${ }^{26}$ and comparing the calculated composition to the composition measured using energy dispersive X-ray spectroscopy.

Transmission Electron Microscopy. Select areas of wire arrays were mechanically removed with a razor blade and dispersed in isopropyl alcohol. After drop casting the solution onto $\mathrm{Si}$ substrates and allowing the solvent to evaporate, a $20 \mathrm{~nm}$ layer of $\mathrm{Al}_{2} \mathrm{O}_{3}$ was deposited using atomic layer deposition. Radial and axial cross sections of single wires were then prepared using standard focused ion beam milling techniques in either a FEI Nova 600 or FEI Versa 3D dual beam system. Transmission electron microscopy characterization in this work was done on a JEOL 2100-F $200 \mathrm{kV}$ FE-TEM and a FEI Technai TF30UT 300 kV FE-TEM.

\section{RESULTS AND DISCUSSION}

Figure 1 depicts the morphology of $\mathrm{Si}_{1-x} \mathrm{Ge}_{x}$ wires with increasing $\mathrm{GeCl}_{4}$ flow as the flow of $\mathrm{SiCl}_{4}$ was held constant. At low $\mathrm{GeCl}_{4}$ flow rates, the wire arrays appear to be largely identical to their $\mathrm{Si}$ counterparts, but, as this rate is increased, the morphology of the wires gradually change from vertical to heavily tapered and faceted sidewalls. The growth rate also changes dramatically, falling from $7 \mu \mathrm{m} \mathrm{min}^{-1}$ to $1 \mu \mathrm{m} \mathrm{min}^{-1}$ as Ge molar flow fraction was increased to $18.6 \%$, and attempts to grow with a gas phase Ge molar fraction of $25.7 \%$ resulted in little to no growth. The changes in morphology and growth rate were unexpected and became a significant focus of our investigation. As expected, the Ge content of the wire arrays increases with increasing Ge flow. The calculated gas phase composition $([\mathrm{Ge}] /[\mathrm{IV}])$ is always greater than that of the resulting wire array. The difference could be the result of differences between the reactivity of chlorogermane and chlorosilane on the catalyst or the hot reactor tube sidewalls, leading to differences in the supersaturated catalyst or gas phase compositions, respectively.

As the growth time is increased at $[\mathrm{Ge}] /[\mathrm{IV}]=18.6 \%$, tapering of the wire continues, with large sidewall facets oriented perpendicular to the growth direction along the length of the wire and a clear reduction in the volume of the catalyst particle (Figure 2). Despite the tapering, the wires can be grown to $60 \mu \mathrm{m}$ in height, which has been shown by Kelzenberg et al. ${ }^{27}$ to be necessary for full absorption of the solar spectrum. Reports of $\mathrm{Si}$ and $\mathrm{SiGe}$ tapered nanowire growth have attributed tapered wires to undesired sidewall 

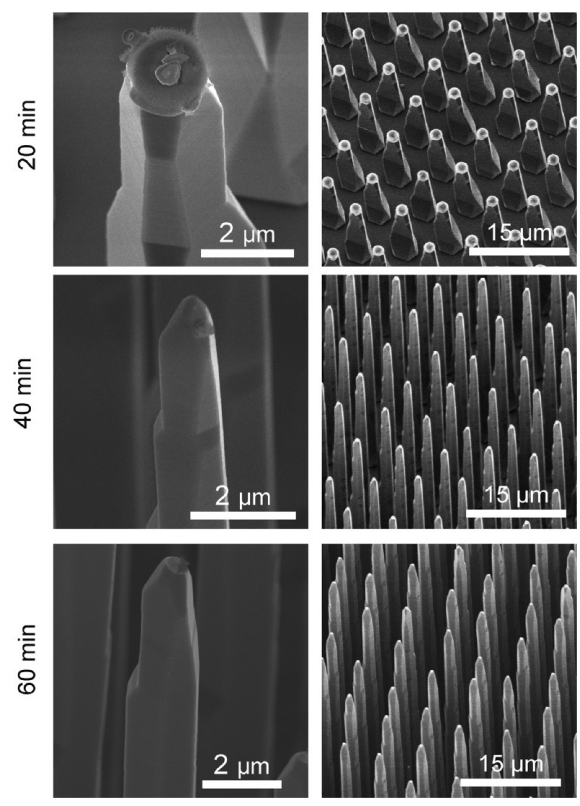

Figure 2. Wire arrays grown at $[\mathrm{Ge}] /[\mathrm{IV}]=18.6 \%$ for an extended period of time as imaged with scanning electron microscopy. The wires have a highly faceted, tapered morphology that persists over long growth times with minimal catalyst volume left after longer growth times.

deposition $^{10,28}$ and in situ etching of the metal catalyst. ${ }^{10,29}$ Hannon et al. observed similar faceting in Si nanowires after introducing a growth interruption, ${ }^{30}$ which they attributed to catalyst migration between the first and second growth phase. Pure Si microwire arrays were grown at elevated temperatures of 1050 and $1100{ }^{\circ} \mathrm{C}$ to encourage etching and evaporation of the catalyst during the growth process. The resulting wire arrays had morphologies more or less identical to those observed for the $\mathrm{SiGe}$ wire arrays, clear evidence of increased catalyst removal with higher $\mathrm{GeCl}_{4}$ flow rates. The sidewall faceting likely results from competing energetics when catalyst material is removed; cylindrical growth is normally stable, ${ }^{31}$ but the catalyst size, and therefore shape, is perturbed until it is energetically favorable for the catalyst diameter to reduce, returning to the preferred shape while creating nonvertical solid wire surfaces. A similar effect is likely responsible for the wide wire bases, due to the difference in the surface energy between the catalyst particle and the $\mathrm{SiO}_{2}$ growth mask during initiation compared to the vapor environment during growth. Reducing the $\mathrm{Si}_{1-x} \mathrm{Ge}_{x}$ growth temperature to $950{ }^{\circ} \mathrm{C}$ was also attempted, and resulted in a large increase in disordered growth compared to perfect, vertical wire array growth, and we could not fairly compare its effects on the wire morphology. We attribute this change to decreased $\mathrm{HCl}$ sidewall etching. Attempts to grow pure $\mathrm{Ge}$ microwire arrays with $\mathrm{Cu}$ catalysts at lower temperatures $\left(800{ }^{\circ} \mathrm{C}\right)$ resulted in similarly disordered growths. $^{32}$

The bulk crystallinity and phase purity of the wire arrays were characterized with X-ray diffraction. All wire arrays are epitaxial with respect to the substrate, but in some cases multiple $\mathrm{Si}_{1-x} \mathrm{Ge}_{x}$ phases are observed. Two representative reciprocal space maps of wire arrays are presented in Figure 3. The reciprocal space map of the symmetric (111) peak of the highly tapered $\mathrm{Si}_{0.91} \mathrm{Ge}_{0.09}$ wires indicates the wires are single phase and epitaxial with respect to the $\mathrm{Si}$ (111) substrate (Figure 3a). A partial determination of the strain state of the
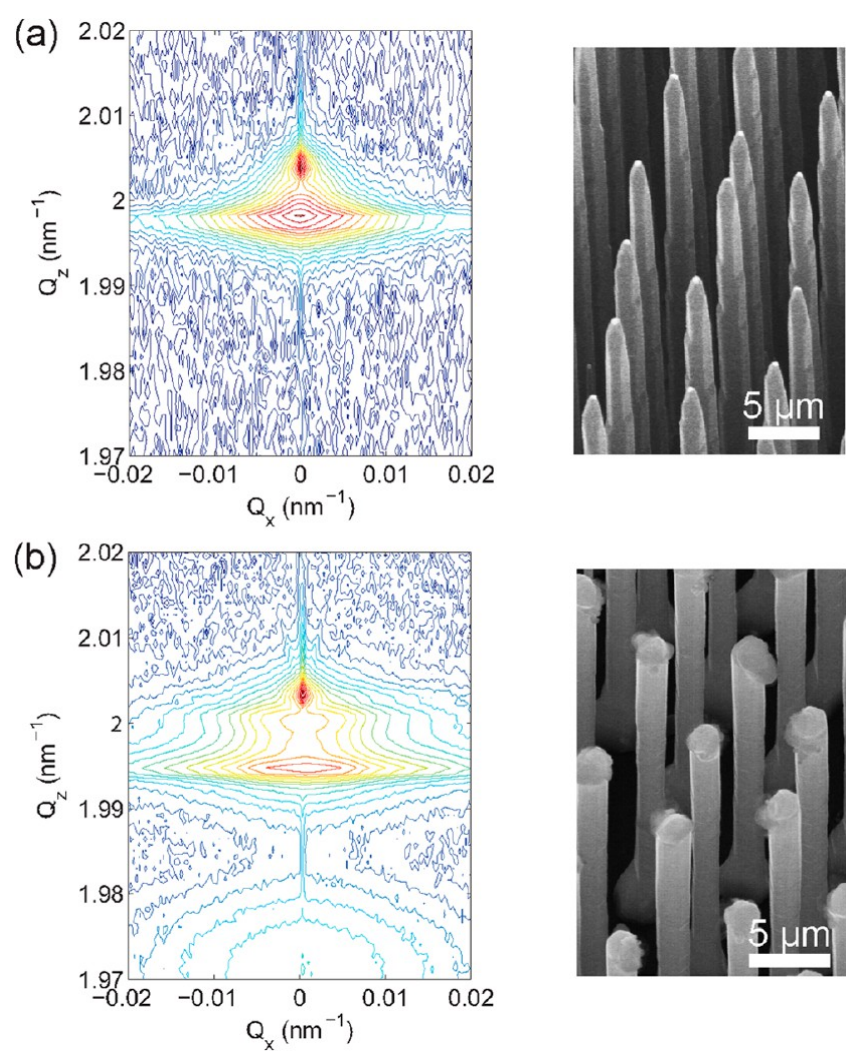

Figure 3. High resolution X-ray diffraction reciprocal space maps. (a) Symmetric (111) peaks of the $\mathrm{Si}_{0.91} \mathrm{Ge}_{0.09}$ wire array. This map is qualitatively representative of all single-phase wire arrays. The wires are fully relaxed. (b) Symmetric (111) peaks of a $\mathrm{Si}_{0.9} \mathrm{Ge}_{0.1}$ wire array with a second $\mathrm{Si}_{1-x} \mathrm{Ge}_{x}$ peak at lower intensity and higher Ge content.

$\mathrm{Si}_{0.91} \mathrm{Ge}_{0.09}$ wire array using the symmetrical (111) and asymmetrical (135) peak positions shows that the wires are fully relaxed. In the second case, the shorter $\mathrm{Si}_{0.9} \mathrm{Ge}_{0.1}$ wire array appears to have some residual $\mathrm{Cu}$ catalyst, and the reciprocal space map indicates a second phase with significantly higher $\mathrm{Ge}$ content at much lower intensity (Figure 3b). While the dominant Si-rich phase is fully relaxed, the strain state of the Ge-rich phase could not be determined due to the low contribution to the diffracted signal. Overall, the presence of a Ge-rich phase did not correspond to any specific growth conditions or morphological features. To investigate the origin of this effect, cross sections of individual wires were prepared and characterized with transmission electron microscopy.

Transmission electron microscopy imaging of radial and axial cross sections taken along the length of a single $\mathrm{Si}_{0.91} \mathrm{Ge}_{0.09}$ wire seen in Figure 4 are single crystalline and phase pure, consistent with the X-ray diffraction measurements. Pure Si nano- and microwires have been observed to be hexagonal or dodecagonal, corresponding to a combination of (110) and (112) facets. ${ }^{33,34}$ By comparing a selected area diffraction pattern and transmission electron microscopy images, the radial facets along the length of a single $\mathrm{Si}_{0.91} \mathrm{Ge}_{0.09}$ wire can also be indexed to the (110) and (112) directions. Importantly, we observed no evidence of crystalline defects in the bulk of the wires which could result from strain relief, suggesting that the strain relieves outward from the substrate axis since the wires present tractionfree surfaces in these directions. Furthermore, we observed no evidence of stacking fault or twin formation associated with the surface faceting. ${ }^{35}$ Axial cross sections along the length of wires 


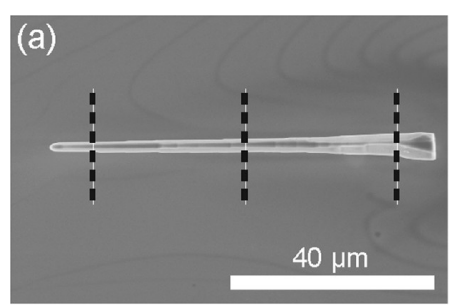

(b)
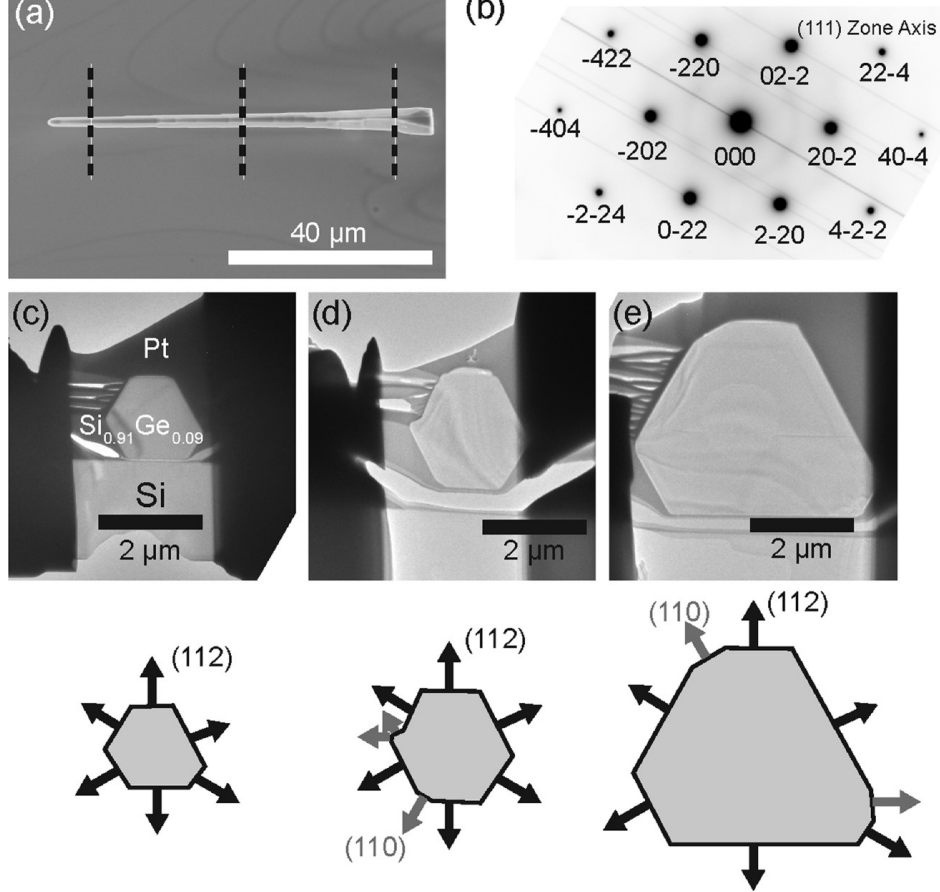

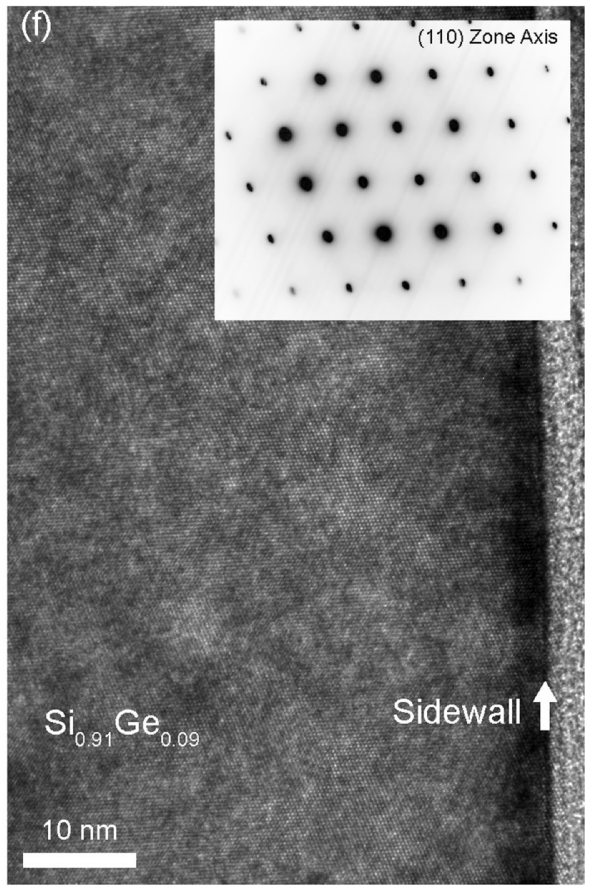

Figure 4. Radial and axial cross sections along the length of a single $\mathrm{Si}_{0.91} \mathrm{Ge}_{0.09}$ wire were characterized with transmission electron microscopy. (a) Scanning electron micrograph of wire with dashed lines overlaid on approximate radial cross section locations. (b) Selected area diffraction patterns lack any features indicative of the presence of crystallographic defects. $(\mathrm{c}, \mathrm{d}, \mathrm{e})$ Transmission electron micrographs of each radial cross section and a corresponding schematic of indexed sidewall facets below. (f) Axial cross section of a second $\mathrm{Si}_{0.91} \mathrm{Ge}_{0.09}$ wire and a corresponding selected area diffraction pattern. The arrow marks the location of the wire sidewall and is oriented in the [111] growth direction.
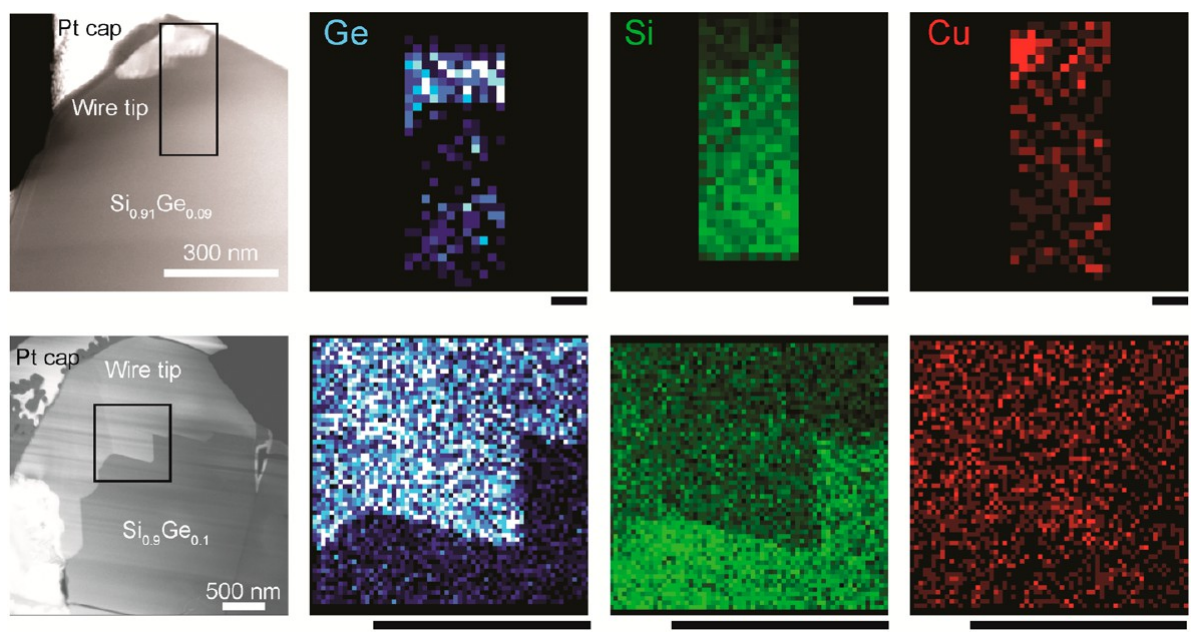

Figure 5. Axial cross sections of $\mathrm{Si}_{0.91} \mathrm{Ge}_{0.09}$ (top row) and $\mathrm{Si}_{0.9} \mathrm{Ge}_{0.1}$ (bottom row) wires representative of the single and double phase wire arrays, respectively. High angle annular dark field images collected with scanning transmission electron microscopy (left) of each of the wire tips reveals clear compositional contrast between the tip and the bulk. Energy-dispersive spectroscopic mapping confirms this finding, revealing a Ge-rich crystal nucleating at the very tip of the wire in both cases, with minimal $\mathrm{Cu}$ incorporation except at the catalyst location. Point and area spectra collected in the Ge-rich regions for the single and double phase wires show compositions of $\mathrm{Si}_{0.43} \mathrm{Ge}_{0.57}$ and $\mathrm{Si}_{0.22} \mathrm{Ge}_{0.78}$, respectively. Scale bars below each map measure $50 \mathrm{~nm}$.

with and without an observed Ge-rich phase in X-ray diffraction were also defect free and phase pure, without any evidence of sidewall epitaxy.

However, closer examination of the wire tips reveals the presence of a region which is compositionally distinct from the bulk of the wire or the $\mathrm{Cu}$ catalyst, regardless of whether the wires appeared to be single phase or double phase in X-ray diffraction measurements (Figure 5). The presence of this phase is clearly seen in high angle annular dark field imaging as a region appearing brighter than the bulk of the wire, suggesting significant compositional contrast, and the interface between the two regions appears to be abrupt. Energy-dispersive X-ray spectroscopic mapping of $\mathrm{Ge}, \mathrm{Si}$, and $\mathrm{Cu}$ reveals significant $\mathrm{Ge}$ enrichment in these regions compared to the bulk of the wire, sharp interfaces between the two regions, and no $\mathrm{Cu}$ content except beyond the noise level at the catalyst location. Point and area spectra taken from the Ge-rich regions reveal enrichment of up to $\mathrm{Si}_{0.43} \mathrm{Ge}_{0.57}$ and $\mathrm{Si}_{0.22} \mathrm{Ge}_{0.78}$ for the single and double 
phase wires, respectively. These observations imply that the catalyst is Ge-rich during the growth process, and the second phase forms either after precursor flow has ceased or as the sample is cooled.

As discussed earlier, the highest Ge content of $12 \%$ was achieved at $[\mathrm{Ge}] /[\mathrm{IV}]=18.6 \%$, and attempts to grow with $[\mathrm{Ge}] /[\mathrm{IV}]=25.7 \%$ resulted in little to no growth. Our observations, namely, the tapering due to catalyst etching with increasing chlorogermane flow and evidence of a Ge-rich catalyst during growth, strongly suggest that $\mathrm{Si}_{1-x} \mathrm{Ge}_{x}$ wire arrays are limited to $\leq 12 \% \mathrm{Ge}$ content when grown with $\mathrm{Cu}$ catalysts and chlorinated precursors at atmospheric pressure. There are several possible explanations for this. Examination of the $\mathrm{Cu}-\mathrm{Si}$ and $\mathrm{Cu}-\mathrm{Ge}$ phase diagrams shows a large difference in eutectic temperature $\left(802{ }^{\circ} \mathrm{C}\right.$ vs $\left.640{ }^{\circ} \mathrm{C}\right)$ and a small difference in the solubility of $\mathrm{Si}$ and $\mathrm{Ge}$ in liquid $\mathrm{Cu}(31 \%$ vs $36 \%$ ), both of which could play a role in the enrichment of the $\mathrm{Cu}$ catalyst and the reduction in growth rate due to a smaller driving force for nucleation of Ge-rich versus Si-rich alloys. Furthermore, at growth temperatures, the liquid catalyst droplet is saturated with $\mathrm{Si}$ before precursors are introduced because it is in direct contact with the Si substrate, which favors initial Sirich supersaturation. Reducing the $\mathrm{SiCl}_{4}$ flow rate while keeping the $\mathrm{GeCl}_{4}$ flow rate constant did not result in higher compositional content. Once growth begins, the strain energy of nucleating alloy material with increased Ge content may play a key role in preventing higher Ge incorporation as the size of the wires leads to their strain relief behavior being more bulklike. This would explain the $\mathrm{Ge}$ enrichment of the catalyst compared to the growing solid wire material.

\section{CONCLUSION}

In conclusion, vertically aligned $\mathrm{Si}_{1-x} \mathrm{Ge}_{x}$ wire arrays were grown with atmospheric pressure, $\mathrm{Cu}$-catalyzed vapor-liquidsolid growth with chlorosilane and chlorogermane precursors over $1 \mathrm{~cm}^{2}$ areas. Increased $\mathrm{GeCl}_{4}$ flow rate led to $\mathrm{Ge}$ incorporation of up to $12 \%$ with a large reduction in the growth rate. The highly faceted, tapered morphology was linked to in situ evaporation and etching of the catalyst particle. Ge-rich epitaxial crystals were found near the tips of the microwires, leading us to speculate that the catalyst is Ge-rich during the growth process. Alternative catalyst materials, such as $\mathrm{Au}$, or precursor choices could allow for increased Ge content, although their effect on the electronic quality and uniformity of the array growth are negative and unknown, respectively. $\mathrm{Si}_{0.89} \mathrm{Ge}_{0.11}$ microwires should allow for lattice and coefficient of thermal expansion matched growth of $\mathrm{GaP}$ to allow for integration of III-V materials for photovoltaic and optoelectronic applications. ${ }^{36}$

\section{ASSOCIATED CONTENT}

\section{S Supporting Information}

SEM images of attempts to grow high Ge content wire arrays, SEM images of $\mathrm{Si}$ wire arrays grown at high temperature, reactor schematic, and photoconductivity measurements are included in the Supporting Information. The Supporting Information is available free of charge on the ACS Publications website at DOI: 10.1021/acs.cgd.5b00097.

\section{AUTHOR INFORMATION}

\section{Corresponding Author}

*E-mail: haa@caltech.edu.

\section{Present Address}

${ }^{\#}$ Daniel B. Turner-Evans, Janeilia Farm Research Campus, Howard Hughes Medical Institute, Ashburn, VA 20147, United States.

\section{Author Contributions}

The manuscript was written through contributions of all authors. All authors have given approval to the final version of the manuscript. Christopher T. Chen and Hal S. Emmer contributed equally.

\section{Notes}

The authors declare no competing financial interest.

\section{ACKNOWLEDGMENTS}

Special thanks goes to Dr. Virginia Altoe and Carol Garland for their assistance with TEM characterization. Critical support and equipment were provided by the Kavli Nanoscience Institute. This work benefited from use of the Applied Physics and Materials Science Department's Transmission Electron Microscopy Facility. This material is based upon work supported in part by the National Science Foundation (NSF) and the Department of Energy (DOE) under NSF CA No. EEC1041895. Any opinions, findings and conclusions or recommendations expressed in this material are those of the authors and do not necessarily reflect those of NSF or DOE. Work at the Molecular Foundry was supported by the Office of Science, Office of Basic Energy Sciences, of the U.S. Department of Energy under Contract No. DE-AC02-05CH11231.

\section{REFERENCES}

(1) Wagner, R. S.; Ellis, W. C. Appl. Phys. Lett. 1964, 4, 89-90.

(2) Putnam, M. C.; Boettcher, S. W.; Kelzenberg, M. D.; TurnerEvans, D. B.; Spurgeon, J. M.; Warren, E. L.; Briggs, R. M.; Lewis, N. S.; Atwater, H. A. Energy Environ. Sci. 2010, 3, 1037.

(3) Spurgeon, J. M.; Boettcher, S. W.; Kelzenberg, M. D.; Brunschwig, B. S.; Atwater, H. A.; Lewis, N. S. Adv. Mater. 2010, 22, 3277-3281.

(4) Boettcher, S. W.; Spurgeon, J. M.; Putnam, M. C.; Warren, E. L.; Turner-Evans, D. B.; Kelzenberg, M. D.; Maiolo, J. R.; Atwater, H. A.; Lewis, N. S. Science 2010, 327, 185-187.

(5) Hersee, S. D.; Fairchild, M.; Rishinaramangalam, A. K.; Ferdous, M. S.; Zhang, L.; Varangis, P. M.; Swartzentruber, B. S.; Talin, A. A. Electron. Lett. 2009, 45, 75.

(6) Boukai, A. I.; Bunimovich, Y.; Tahir-Kheli, J.; Yu, J.-K.; Goddard, W. A.; Heath, J. R. Nature 2008, 451, 168-171.

(7) Lee, E. K.; Yin, L.; Lee, Y.; Lee, J. W.; Lee, S. J.; Lee, J.; Cha, S. N.; Whang, D.; Hwang, G. S.; Hippalgaonkar, K.; Majumdar, A.; Yu, C.; Choi, B. L.; Kim, J. M.; Kim, K. Nano Lett. 2012, 12, 2918-2923.

(8) Amato, M.; Palummo, M.; Rurali, R.; Ossicini, S. Chem. Rev. 2014, 114, 1371-1412.

(9) Lew, K.-K.; Pan, L.; Dickey, E. C.; Redwing, J. M. Adv. Mater. 2003, 15, 2073-2076.

(10) Lew, K.; Pan, L.; Dickey, E. C.; Redwing, J. M. J. Mater. Res. 2006, 21, 2876-2881.

(11) Zhang, X.; Lew, K.-K.; Nimmatoori, P.; Redwing, J. M.; Dickey, E. C. Nano Lett. 2007, 7, 3241-3245.

(12) Kawashima, T.; Imamura, G.; Fujii, M.; Hayashi, S.; Saitoh, T.; Komori, K. J. Appl. Phys. 2007, 102, 124307.

(13) Qi, C.; Goncher, G.; Solanki, R.; Jordan, J. Nanotechnology 2007, $18,075302$.

(14) Hsiao, T.-K.; Chang, H.-K.; Liou, S.-C.; Chu, M.-W.; Lee, S.-C.; Chang, C.-W. Nat. Nanotechnol. 2013, 8, 534-538.

(15) Givan, U.; Patolsky, F. Nano Lett. 2009, 9, 1775.

(16) Wen, C.-Y.; Reuter, M. C.; Bruley, J.; Tersoff, J.; Kodambaka, S.; Stach, E. A.; Ross, F. M. Science 2009, 326, 1247-1250.

(17) Geaney, H.; Mullane, E.; Ramasse, Q. M.; Ryan, K. M. Nano Lett. 2013, 13, 1675-1680. 
(18) Kayes, B. M., PhD. Dissertation, California Institute of Technology, 2009.

(19) Kendrick, C. E.; Redwing, J. M. J. Cryst. Growth 2011, 337, 1-6.

(20) Gentile, P.; Solanki, a; Pauc, N.; Oehler, F.; Salem, B.; Rosaz, G.; Baron, T.; Den Hertog, M.; Calvo, V. Nanotechnology 2012, 23, 215702.

(21) Kayes, B. M.; Filler, M. A.; Putnam, M. C.; Kelzenberg, M. D.; Lewis, N. S.; Atwater, H. A. Appl. Phys. Lett. 2007, 91, 103110.

(22) Eichfeld, S. M.; Shen, H.; Eichfeld, C. M.; Mohney, S. E.; Dickey, E. C.; Redwing, J. M. J. Mater. Res. 2011, 26, 2207-2214.

(23) Park, W.; Zheng, G.; Jiang, X.; Tian, B.; Lieber, C. M. Nano Lett. 2008, 8, 3004-3009.

(24) Shenai, D. V.; DiCarlo, R. L.; Power, M. B.; Amamchyan, A.; Goyette, R. J.; Woelk, E. J. Cryst. Growth 2007, 298, 172-175.

(25) Soman, R.; Reisman, A.; Temple, D.; Alberti, R. J. Electrochem. Soc. 2000, 147, 1847.

(26) Zhylik, A.; Benediktovich, A.; Ulyanenkov, A.; Guerault, H.; Myronov, M.; Dobbie, A.; Leadley, D. R.; Ulyanenkova, T. J. Appl. Phys. 2011, 109, 123714.

(27) Kelzenberg, M. D.; Boettcher, S. W.; Petykiewicz, J. A.; TurnerEvans, D. B.; Putnam, M. C.; Warren, E. L.; Spurgeon, J. M.; Briggs, R. M.; Lewis, N. S.; Atwater, H. A. Nat. Mater. 2010, 9, 239-244.

(28) Potié, A.; Baron, T.; Latu-Romain, L.; Rosaz, G.; Salem, B.; Montès, L.; Gentile, P.; Kreisel, J.; Roussel, H. J. Appl. Phys. 2011, 110, 024311.

(29) Pan, L.; Lew, K.; Redwing, J.; Dickey, E. J. Cryst. Growth 2005, $277,428-436$.

(30) Hannon, J. B.; Kodambaka, S.; Ross, F. M.; Tromp, R. M. Nature 2006, 440, 69-71.

(31) Nebol'sin, V. A.; Shchetinin, A. A. Inorg. Mater. 2003, 39, 899903.

(32) Turner-Evans, D. B., PhD. Dissertation, California Institute of Technology, 2013.

(33) Wu, Y.; Cui, Y.; Huynh, L.; Barrelet, C. Nano Lett. 2004, 4, 433-436.

(34) Ross, F. M.; Tersoff, J.; Reuter, M. C. Phys. Rev. Lett. 2005, 95, $1-4$.

(35) Shin, N.; Chi, M.; Howe, J. Y.; Filler, M. A. Nano Lett. 2013, 13, $1928-1933$.

(36) Carlin, A. M.; Grassman, T. J.; Brenner, M. R.; Grandal, J.; Ratcliff, C.; Yang, L.; Mills, M.; Sharma, P.; Fitzgerald, E. A.; Ringel, S. A. In 2012 38th IEEE Photovoltaic Specialists Conference; IEEE, 2012; pp 000918-000921. 